\title{
Number and position of wounds on honey bee (Apis mellifera) pupae infested with a single Varroa mite
}

\author{
GHAZWAN KANBAR and Wolf ENGELS \\ Zoological Institute, University of Tübingen, Auf der Morgenstelle 28, D-72076 Tübingen, Germany; \\ e-mail: wolf.engels@uni-tuebingen.de
}

Key words. Apis mellifera, brood infestation, haemolymph-sucking mite, Varroa destructor, parasitic pupal wounds, evolution of host-parasite relations

\begin{abstract}
The wounds inflicted on pupae in capped brood cells of the honey bee, Apis mellifera, infested with a single female of the ectoparasitic mite, Varroa destructor, were investigated after visualisation by vital staining with trypan blue. On average the mites made two integumental perforations for feeding on prepupae and one on pupae. Most of the punctures were on particular ventral sites on the abdomen. Possible reasons for this pronounced preference and the evolutionary aspects of this highly specialised parasite-host relationship are discussed.
\end{abstract}

\section{INTRODUCTION}

The mite Varroa destructor (Anderson \& Trueman, 2000) is a haemolymph-sucking ectoparasite of the Asian honey bee, Apis cerana (Rath, 1999). Due to the intercontinental bee trade, this mite was transferred to a new host Apis mellifera and is now distributed worldwide, causing severe problems as it damages honey bee colonies (Morse \& Nowogrodzki, 1999). Reproduction of the mite is restricted to capped bee brood cells (Ifantidis \& Rosenkranz, 1988), which are invaded by female mites a few hours prior to their being sealed (Aumeier et al., 2002). These mites puncture the integument of last instar bee larvae, prepupae and pupae with their chelicerae and the perforations are repeatedly used by the Varroa female and her offspring to feed on haemolymph of the host (Donzé \& Guerin, 1994).

Because these processes occur within capped brood cells, transparent artificial brood cells were developed to observe this parasitism (Abbas \& Engels, 1990; Donzé \& Guerin, 1994). However, the integumental wounds on the host bee are difficult to detect. Therefore, their number and exact position could not be studied in detail. This became possible by using vital staining of the wounds with trypan blue (Kanbar \& Engels, 2004). Here we present data on the position and number of cuticular punctures on preimaginal host bees infested by a single female mite. The results are discussed under aspects of evolutionary adaptations in this parasite-host relationship.

\section{MATERIAL AND METHODS}

We used heavily infested colonies of Apis mellifera carnica in the apiaries of the University of Tübingen. In the experimental hives, which were not treated with Varroa control measures in spring and early summer, many brood cells contained Varroa destructor mites. Combs with capped brood were collected and stored in an incubator at $35^{\circ} \mathrm{C}$ and $80 \%$ humidity. More than 2,000 sealed worker and drone brood cells were carefully opened and inspected for the presence of mites. From about 1,100 cells, which only one female mite had invaded, the host bee was removed and incubated at room temperature for 30 min in a ringer medium containing $0.01 \%$ trypan blue (Chroma, Stuttgart, \# 1 F 577). By this procedure epidermal cells damaged (compare Roche Lexikon Medizin, 1999, p. 1602) by mite-made punctures, became vital-stained (Kanbar \& Engels, 2004). The integumental wounds of the host bee appeared as small blue spots. They were studied under a photo-stereomicroscope (Wild M 8) at up to $80 \times$ magnification.

\section{RESULTS}

\section{Appearance of trypan blue stained wounds}

The trypan blue staining of integumental perforations on late L5 feeding instars was unsuccessful. But the wounds of prepupal stages onwards were successfully vital stained and could be easily detected as small blue dots. Shortly after the pupal moult, the central hole of these perforations measured about $50-60 \mu \mathrm{m}$ in diameter (Fig. 1a). Because the mites repeatedly use this feeding site, more surrounding epidermal cells become damaged and the wound enlarges in the course of the pupal phase (Fig. 1b). In brownish pigmented pupae (Fig. 1c) the perforations may reach a diameter of $80-100 \mu \mathrm{m}$, or more.

\section{Frequency of punctures on host bees}

The percentage of host individuals with Varroa-made perforations, visualised by the trypan blue staining, increased in the course of preimaginal development (Fig. 2). Over 3/4 of all infested prepupae had integumental wounds. In later pupal stages wounds were found on nearly all bees. In the drone brood there was always a slightly higher fraction of individuals with punctures than in the worker brood.

\section{Position of the wounds on the host bee}

There were no punctures on the anterior region, comprising head, thorax and the first abdominal segment, or the last abdominal segments of prepupae (Fig. 3). Perforations were found on abdominal segments 2 to 9 , mostly on the left ventral side. About $40 \%$ of all wounds were on the $6^{\text {th }}$ abdominal segment of both worker and drone pupae.

On pupae a high percentage of the wounds was on the $2^{\text {nd }}$ abdominal segment, indicating that the female mite had a different preferred feeding site on pupae. Very few perforations were found on segments 3 to 5 of the abdomen (Fig. 4). Again nearly all the punctures were on the sternites, of worker as well as of drone pupae, and $60 \%$ were positioned more towards the left side. Surprisingly, on about $1 / 4$ of the worker pupae the wounds were located on the mesothorax (Fig. 4). We want to emphasise that no males in the over 1,100 host bees investigated 

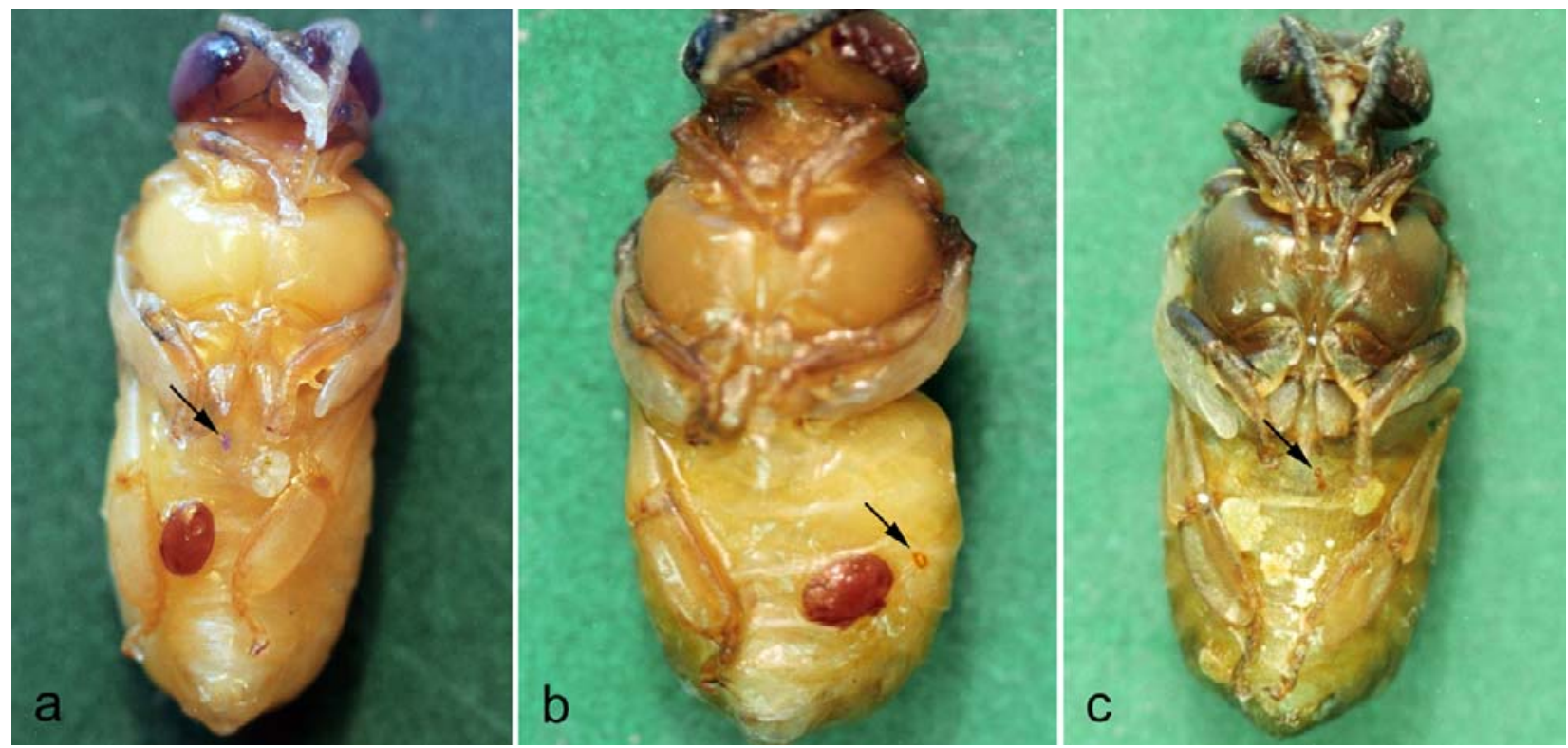

Fig. 1. Honey bee (Apis mellifera) drone pupae in ventral view, vital stained with trypan blue to visualise integumental wounds (arrows) made by Varroa females for sucking host haemolymph. (a) Pupa about 16 days old with one perforation on the $2^{\text {nd }}$ abdominal segment, (b) pupa about 18 days old with one perforation on the 4th abdominal segment, (c) pupa about 20 days old with two perforations on the $2^{\text {nd }}$ abdominal segment. Brown adult Varroa females are seen in a and b, pale nymphal mites in a and c.

for this study and the one thousand or more drone pupae inspected for other reasons in our laboratory over the last five years had Varroa-made perforations on their thorax.

\section{Number of wounds per host bee}

The number of punctures on late feeding and spinning L5 bee larvae could not be determined with certainty. On prepupae we counted one to three perforations, with on average two. There was no difference in the number of wounds between worker and drone individuals. On the majority of pupae there was only one wound present. Two perforations (Fig. 1c) were found on $1.7 \%$ and $2.7 \%$ of about 600 pupae of workers and 600 of drones, respectively. Three wounds were detected on only one worker and one drone pupa.

\section{DISCUSSION}

\section{Number of punctures}

There are few records in the literature on the number of perforations made by Varroa females as permanent feeding sites on capped honey bee brood, especially in cells infested by a single

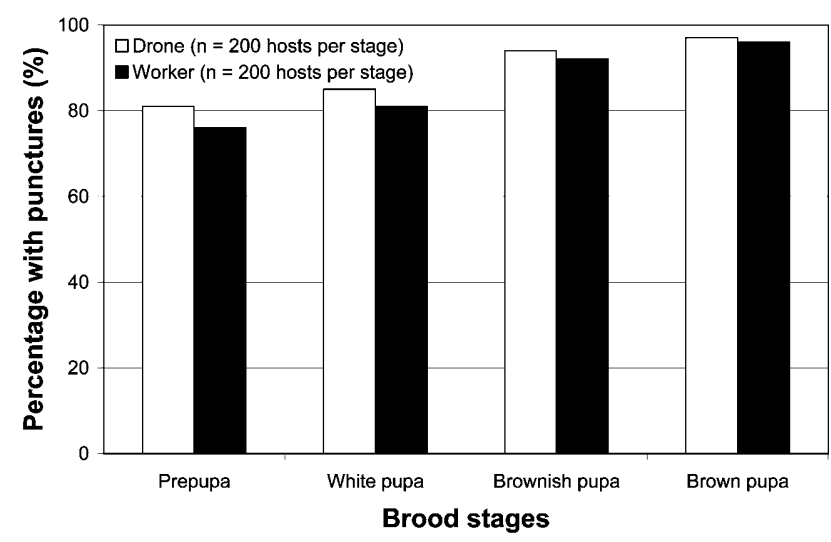

Fig. 2. Percentage of preimaginal brood stages of the honey bee (Apis mellifera) on which Varroa-made integumental wounds were detected by vital staining with trypan blue. mite. There are on average two on prepupae and one on pupae removed from normal wax cells of combs in naturally infested colonies showing severe symptoms of varroatosis. Donzé \& Guerin (1994) mentioned higher numbers, but they used artificial transparent and round brood cells for their video recordings. Nevertheless, they observed more wounds on prepupae than pupae. The fact that we detected only one perforation on nearly all the worker and drone pupae we examined may be because the female mite prepares this feeding site for long-term use. Immediately after the pupal moult the Varroa female pushes the hindlegs of the bee host aside and punctures an abdominal sternite (Donzé \& Guerin, 1997). According to these authors, this is performed quickly, probably because sclerotisation of the cuticle makes puncturing of the cuticle more difficult. Another question is how many punctures are present on brood infested by more than one mite. Up to 20 Varroa females may invade a drone brood cell (Duay et al., 2002).

\section{Position of the wounds}

Most of the mite inflicted wounds on prepupae were on the 6th and on pupae on the 2nd abdominal sternite. The latter confirms the video records of Donzé \& Guerin (1994) who, how-

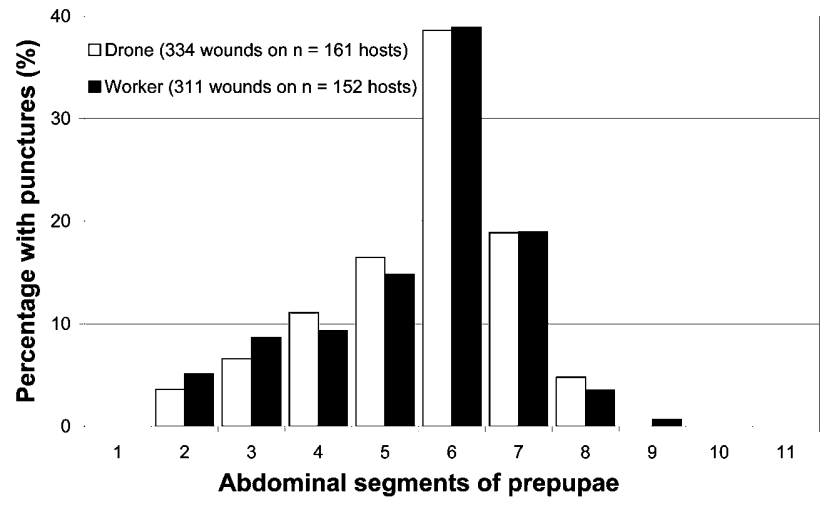

Fig. 3. Percentage of abdominal segments of prepupal host bees (Apis mellifera) with Varroa-made integumental wounds. 
a

Drone pupae

$(n=560)$

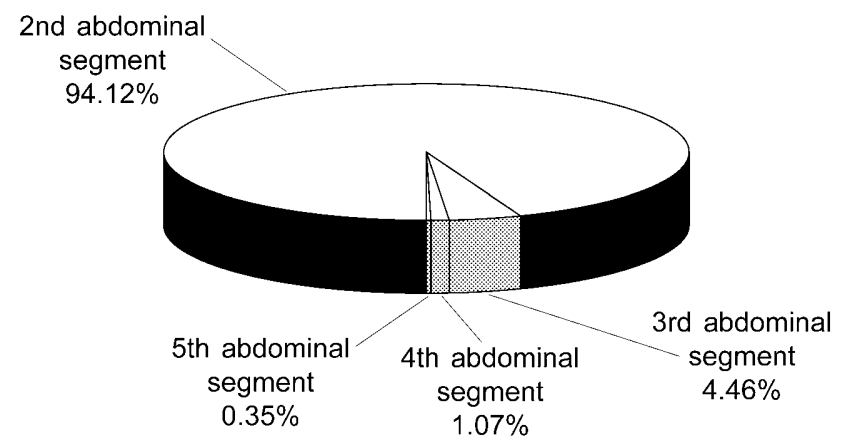

Worker pupae

$(n=545)$

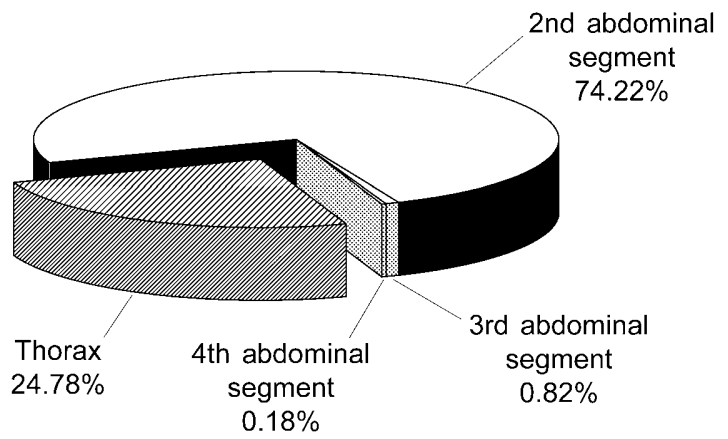

Fig. 4. Pie diagram of the percentage of Varroa-made integumental wounds on various parts of the body of bee pupae (Apis mellifera). The $2^{\text {nd }}$ abdominal segment is the preferred site on drone (a) and worker pupae (b) but perforations on the thorax only occurred on worker pupae.

ever, named this abdominal segment 5 because they included the three thoracic segments. Such an exact positioning of the feeding site on the host's body is probably a result of selection. Unfortunately, nothing is known about the wounds made by Varroa females feeding on the brood of its original host species, Apis cerana (Rath, 1999). We assume that the position of the perforations on A. mellifera prepupae and pupae provides optimum for haemolymph uptake by the mites.

\section{Mite orientation towards the site of the puncture}

Varroa mites can only reproduce in capped brood cell of honey bees. There is limited space, but the conditions are absolutely stable: a wax-lined narrow cell, high humidity and constant temperature of about $35^{\circ} \mathrm{C}$. The only source of nutrition for the female mite, and later on her progeny, is one preimaginal host bee. In order to feed on the bee's haemolymph, the body wall of the host has to be perforated. It is not surprising that the evolution of this very specific parasite-host relationship resulted in the mite selecting a particular feeding site, which is located with great accuracy. Varroa females are capable of accurately locating and puncturing the bee's integument at a few specific sites, presumably optimum for haemolymph uptake.

What determines these preferred sites, and how does the parasite recognise them? The $2^{\text {nd }}$ abdominal sternite of pupae in particular is chosen with remarkable constancy (Fig. 4). Interestingly, preferential sucking of haemolymph from this segment in other host insects is also known for related taxa, like mussel mites (Baker, 1991). This raises questions about the special properties of this feeding site. In honey bee pupae the sternite of the $2^{\text {nd }}$ abdominal segment is somewhat stretched over an underlying large haemocoelic cavity. We attempted to puncture the ventral region of the abdomen with a needle and found it was particularly easy on the $2^{\text {nd }}$ sternite. The tendency for the abdominal punctures on pupae to be mostly a little left of the midline suggests an additional and unknown orientation stimulus. More Varroa mites were also found on the left side of the abdomen of adult bees (Delfinado-Baker et al., 1992).

\section{Worker brood infestation in Apis mellifera}

In colonies of $A$. mellifera the parasite-host relationship is evidently still unbalanced (Rosenkranz, 1999). If suffering from varroatosis, they are often co-infected with virus (Martin, 1998). In the original host, the Asian A. cerana, female Varroa mites invade worker brood but reproduce exclusively in drone brood (Koeniger et al., 1981; Tewarson et al., 1982; Boot et al., 1997). Why in A. mellifera colonies Varroa mites are also able to reproduce in worker brood is unknown (Garrido et al., 2001). As shown here, only on worker pupae are 1/4 of the Varroa-caused wounds found on the thorax (Fig. 4).

\section{Ultimate consequences of the injury to bee pupae}

The limited number of wounds made by Varroa mites may be an adaptive trait, because these perforations in the pupal cuticle are routes for microbial infection (Brødsgaard et al., 2000), which will eventually kill the bee, because only towards the end of the pupal phase will a scar form over the wounds (Kanbar \& Engels, 2003). If the adult bee does not emerge from its cell, the mites are trapped in the sealed brood cell, as is observed in heavily infested drone brood of A. cerana (Boecking, 1999). Limited exploitation and minimum damage to the host will therefore increase the fitness of the Varroa female as it does not adversely affect the mite's reproductive potential (Boot et al., 1997). Such factors may have shaped the behaviour of this successful honey bee parasite.

ACKNOWLEDGEMENTS. Our bee colonies were reared and the combs with infested brood were skilfully provided by Imkermeister A. Oelkrug. We appreciate the help of S. Heinle and Wolfram Engels in preparing the figures. We thank R.J. Paxton for critically reading the manuscript.

\section{REFERENCES}

Abbas N.D. \& Engels W. 1990: In vitro rearing of honey bee parasite Varroa jacobsoni. In Veeresh G.K., Mallik B. \& Viraktamath C.A. (eds): Social Insects and the Environment. Oxford \& IBH Publ., New Delhi, p. 459.

Anderson D.L. \& Trueman J.W.H. 2000: Varroa jacobsoni (Acari: Varroidae) is more than one species. Exp. Appl. Acarol. 24: 165-189.

Aumeier P., Rosenkranz P. \& Francke W. 2002: Cuticular volatiles, attractivity of worker larvae and invasion of brood cells by Varroa mites. A comparison of Africanized and European honey bees. Chemoecology 12: 65-75.

BAKER R.A. 1991: Development and life-history strategies in mussel mites (Hydrachnellae: Unionicolidae). In Schuster R. \& Murphy P.W. (eds): The Acari. Chapman \& Hall, London, pp. 65-73.

Boecking O. 1999: Sealing up and non-removal of diseased and Varroa jacobsoni infested drone brood cells is part of the hygienic behaviour in Apis cerana. J. Apic. Res. 38: 159-168. Boot W.J., Tan N.Q., Dien P.C., Huan L.V., Dung N.V., Long L.T. \& BeEtSMA J. 1997: Reproductive success of Varroa jacobsoni in brood of ist original host, Apis cerana, in com- 
parison to that of its new host, Apis mellifera (Hymenoptera: Apidae). Bull. Entomol. Res. 87: 119-126.

Brødsgaard C.J., Ritter W., Hansen H. \& Brødsgaard H.F. 2000: Interactions among Varroa jacobsoni mites, acute paralysis virus, and Paenobacillus larvae and their influence on mortality of larval honeybees in vitro. Apidologie 31: $543-554$.

Delfinado-Baker M., Rath W. \& Boecking O. 1992: The phoretic mites and honeybee grooming behaviour. Int. J. Acarol. 18: $315-322$

Donzé G. \& Guerin P.M. 1994: Behavioral attributes and parental care of Varroa mites parasitizing honey bee brood. Behav. Ecol. Sociobiol. 34: 305-319.

Donzé G. \& Guerin P.M. 1997: Time-activity budgets and space structuring by the different life stages of Varroa jacobsoni in capped brood of the honey bee, Apis mellifera. J. Ins. Behav. 10: $371-393$

Duay P., DeJong D. \& Engels W. 2002: Weight loss in drones (Apis mellifera) multiply infested by Varroa destructor mites. Apidologie 34: 61-65.

Garrido C., Paxton R.J. \& Rosenkranz P. 2001: VarroaReproduktion: Wirtsfaktoren oder Eigenschaften des Parasiten? Apidologie 32: 481-482.

Ifantidis M.D. \& Rosenkranz P. 1988: Reproduktion der Bienenmilbe Varroa jacobsoni (Acarina: Varroidae). Entomol. Gener. 14: 111-122.
Kanbar G. \& Engels W. 2003: Ultrastructure and bacterial infection of wounds in honey bee (Apis mellifera) pupae punctured by Varroa mites. Parasitol. Res. 90: 349-354.

Kanbar G. \& Engels W. 2004: Visualisation by vital staining with trypan blue of wounds punctured by Varroa destructor mites in pupae of the hoeny bee (Apis mellifera). Apidologie 35: $25-29$.

Koeniger N., Koeniger G. \& Wijayagunasekara N.H.P. 1981: Observations on the adaptation of Varroa jacobsoni to its natural host Apis cerana in Sri Lanka. Apidologie 12: 37-40.

MARTIN S. 1998: A population model for the ectoparasitic mite Varroa jacobsoni in honey bee (Apis mellifera) colonies. Ecol. Model. 109: 267-281.

Morse R.A. \& Nowogrodzki R. 1999: Honey Bee Pests, Predators and Diseases. Comstock Cornell University Press, Ithaca, NY, $474 \mathrm{pp}$.

Rath W. 1999: Co-adapation of Apis cerana Fabr. and Varroa jacobsoni Oud. Apidologie 30: 97-110.

Roche LeXIKON MedizIN, $4^{\text {TH }}$ ED. 1999: Trypanblau, engl. trypan blue, zur Vitalitätsprüfung. Urban \& Fischer Verlag, München, p. 1602.

Rosenkranz P. 1999: Honey bee (Apis mellifera L.) tolerance to Varroa jacobsoni Oud. in South America. Apidologie 30: 159-172.

Tewarson N.C., Sing A. \& Engels W. 1982: Reproduction of Varroa jacobsoni in colonies of Apis cerana indica under natural and experimental conditions. Apidologie 23: 161-171.

Received December 3, 2003; revised February 25, 2004; accepted March 18, 2004 